\title{
Modelling the Response of Loblolly Pine to Juvenile Fertilization
}

\author{
John P. McTague*
}

North Carolina State University and Rayonier Inc., USA

\begin{abstract}
This paper presents a dominant height and basal area response function for juvenile (ages 2-8) loblolly pine stands that have been fertilized with a combination dose of $200 \mathrm{lbs} / \mathrm{ac}$ of nitrogen and $50 \mathrm{lbs} / \mathrm{ac}$ of phosphorus. The data used to construct the response functions originated from the Region-wide 2 Study of the North Carolina State University Forest Nutrition Cooperative. The data set included field plots from three physiographic regions and states spanning the southeastern United States from Alabama to Delaware. The dominant height response model is a function of the time elapsed since fertilization (years since treatment) and soil drainage of the Coastal Plain soils. The basal area response model is a function of years since treatment. The response functions must be used sequentially since basal area response is understood as an incremental gain in basal area over the increase in basal area already explained by the response in dominant height. The response in dominant height typically ranges from 1-2 feet, six to eight years after treatment on all soils except the well drained Coastal Plain soils. The total increase in basal area ranges from $10-12 \mathrm{ft}^{2} / \mathrm{ac}$, six to eight years after treatment on all soils except the well drained Coastal Plain soils. The parameters of both models were estimated using the Mixed Models with Repeated Measures methodology.
\end{abstract}

Keywords: loblolly pine, response modelling, fertilization, mixed models.

\section{INTRODUCTION}

Bailey et al. [1] were among the first modellers to construct fertilization response functions. They developed three stand-level projection equations for dominant height, survival, and basal area that were functions of the change in age, soil group, and fertilization dosage

$$
\begin{array}{ll}
\mathrm{H}_{2}= & f\left(\mathrm{H}_{1}, \mathrm{~A}_{1}, \mathrm{~A}_{2}, \text { soil group, fertilization dosage }\right) \\
\mathrm{N}_{2}= & f\left(\mathrm{~N}_{1}, \mathrm{~A}_{1}, \mathrm{~A}_{2}, \text { soil group, fertilization dosage }\right) \\
\mathrm{B}_{2}= & f\left(\mathrm{~B}_{1}, \mathrm{~A}_{1}, \mathrm{~A}_{2}, \text { soil group, fertilization dosage }\right)
\end{array}
$$

where $\mathrm{H}_{\mathrm{i}}, \mathrm{N}_{\mathrm{i}}$, and $\mathrm{B}_{\mathrm{i}}$ are dominant height, trees per acre, and basal area per acre at age $A_{i}$ respectively. There is no sequential order to the functions and each equation is independent of each other. The independence is easily demonstrated since the endogenous variables are only functions of the lagged dependent variable, change in time, plus static variables. The projection equations above may be used for both treated and untreated stands.

Pienaar and Rheney [2] introduced a silvicultural response model that has proven popular for modelling response to intensive site preparation techniques at establishment and mid-rotation treatments.

$$
R=a_{0}(y s t)^{a_{1}} e^{a_{2} y s t}
$$

where

$$
\begin{aligned}
& \mathrm{R}=\text { (treated }- \text { untreated) response in } \mathrm{ft}_{\text {. }} \mathrm{ft}^{2} / \mathrm{ac}, \text { or } \mathrm{ft}^{3} / \mathrm{ac} \\
& \mathrm{yst}=\text { years since treatment or application } \\
& \mathrm{a}_{\mathrm{i}}=\text { parameters to be estimated }
\end{aligned}
$$

*Address correspondence to this author at Rayonier Inc., 1901 Island Walkway, PO Box 728, Fernandina Beach, FL, 32035, USA;

E-mail: johnpaul.mctague@rayonier.com
This function was first described in the forestry literature as the Hoerl special function by Wenger [3]. Sit and PoulinCostello [4] designated this function as a Type II combined exponential and power function. Ratkowsky [5] also catalogued this model as a three-parameter curve with one independent variable and with a maxima or minima. Pienaar and Rheney [2] conditioned the parameters so that $\mathrm{a}_{1}=1$ and $\mathrm{a}_{2}<$ 0 . They stated that the maximum cumulative response is attained when yst $=-1 / \mathrm{a}_{2}$, and that the magnitude of the maximum cumulative response equals the value of $\left(-\mathrm{a}_{0} / \mathrm{a}_{2}\right) \mathrm{e}^{-1}$. The negative $a_{2}$ parameter implies that the response must approach zero, imparting a transient increase or Type ' $\mathrm{C}$ ' response as described by Morris and Lowery [6]. The Type ' $\mathrm{C}$ ' response guarantees that the treated stand will never 'crossover' or display dominant height or basal area attributes below that of the non-treated stand. Provided that the estimated $\mathrm{a}_{2}$ parameter is greater than -0.229 , the cumulative response of the treated stand will exceed the non-treated stand by at least $5 \%$ of the maximum response, even at 25 years past treatment.

The Pienaar and Rheney response functions were embedded within a recursive system of stand-level prediction equations for dominant height, basal area, and stand volume

$$
\begin{aligned}
& H=b_{0}\left(1-e^{-b_{1} A}\right)^{b_{2}}+R_{H} \\
& B=e^{b_{3}+b_{4} / A} H^{b_{5}+b_{6} / A} N^{b_{7}}+R_{B} \\
& V=e^{b_{8}+b_{9} / A} H^{b_{10}} N^{b_{11}+b_{12} / A} B^{b_{13}}
\end{aligned}
$$

where $\mathrm{H}, \mathrm{A}, \mathrm{B}, \mathrm{N}$, and $\mathrm{V}$ are dominant height, stand age, basal area per acre, trees per acre, and stand volume per acre 
respectively. The variables $R_{H}$ and $R_{B}$ refer to the response to dominant height and basal area. Since the stand-level estimate of basal area is a function of dominant height, which in turn is a function of age and $R_{H}$, it is understood that $R_{B}$ is the incremental gain in basal area over the increase in basal area already explained by the response in dominant height. Pienaar and Rheney determined that a response variable for the stand volume equation, $\mathrm{V}$, was not necessary given the effect of $R_{H}$ in explaining $H$, and $B$, and the effect of $R_{B}$ in explaining B. Buford and Burkhart [7] used a similar recursive system approach to model the response of genetic tree improvement on dominant height and stand volume

$$
\begin{aligned}
& \mathrm{H}=f\left(\mathrm{~A}, \mathrm{R}_{\mathrm{Hg}}\right) \\
& \mathrm{V}=f(\mathrm{~A}, \mathrm{~N}, \mathrm{H})
\end{aligned}
$$

where $R_{H g}$ is the response in dominant height due to genetic tree improvement. They likewise concluded after explaining the improvement in $\mathrm{H}$ with $\mathrm{R}_{\mathrm{Hg}}$, a response variable for stand volume equation, $\mathrm{V}$, was not necessary.

Amateis et al. [8] have taken a different approach to modelling the effect of fertilization on the development of dominant height and basal area. They did not create a recursive system of dominant height and basal area equations for both fertilized and unfertilized stands. Rather, they constructed response models for fertilized stands only using $R_{H}$, and $R_{B}$ as dependent variables. Their definition for $R_{H}$ is similiar to that of Pienaar and Rheney [2]. The Amateis et al. [8] definition of $R_{B}$ is quite different. $R_{B}$ is defined as the difference in basal area between a fertilized and unfertilized (control) stand. During their fitting procedure, the increase of basal area in fertilized stands, due to $\mathrm{R}_{\mathrm{H}}$, was unobservable.

When inspecting the system of stand-level equations above described by Pienaar and Rheney [2], it is apparent that the first term on the right-hand-side of Equation (1) describes the height growth of an average untreated stand. Quite likely, one of or a combination of all three estimated $b_{i}$ parameters would change if sufficient observations were available to model dominant height on a plot by plot or stand by stand basis. The mixed modelling approach described by Hall and Bailey [9] and Fang and Bailey [10] presents an opportunity to localize the predictions of Equation (1) to a plot or stand. Using a similar analogy to a fixed model, it is possible make Equation (1) stand-specific by creating (n-1) dummy variables and replacing the $b_{0}$ coefficient with $\left(\alpha_{0}+\right.$ $\alpha_{\mathrm{i}} Z_{\mathrm{i}}$ ) where

$$
Z_{i}= \begin{cases}1 & \begin{array}{l}
\text { if dominant height observation is } \\
\text { located in stand } \mathrm{i}(\mathrm{i}<\mathrm{n})
\end{array} \\
-\quad 1 & \begin{array}{l}
\text { if dominant height observation is } \\
\text { located in stand } \mathrm{n} \\
0
\end{array} \\
\text { otherwise }\end{cases}
$$

In this case, $\mathrm{n}$ represents the total number of groups or stands in the data set and $\alpha_{0}$ is the parameter controlling the mean value (asymptote) over the entire population of all stands. The sum of the $\alpha_{\mathrm{i}} \mathrm{s}$ is conditioned to equal 0 . If inference about a specific stand is not required and it is possible to use the dominant height model for all stands, stand effect may be declared random. Declaring stands to be a random effect is a form of 'blocking' in an experimental design context and it permits the reduction of a large source of variation. Using the terminology adopted by Schabenberger and Pierce [11], the stand would be designated as a cluster. A cluster is defined as a collection of observations that share a stochastic, temporal, spatial, or other association that may be treated as a group. They advocate the application of a twostage concept or mixed model to estimate a populationaverage or global trend and a cluster-specific trend. The mixed model statistical methodology must be used to estimate coefficients and compute variances when one or more of the effects are declared to be random. The objective of this paper is to present an application of the mixed modelling approach. It is well suited to the creation of fertilization response model since it strengthens the signal to noise ratio, making it possible to increase the significance of the estimated coefficients of the response.

\section{METHODS}

The data used to construct the juvenile fertilization model originated from the Region-wide 2 study of the North Carolina State University Forest Nutrition Cooperative [12]. Region-wide 2 was established to study the magnitude and duration of nine fertilization treatments on young developing loblolly pine stands on site-prepared land. The experiment was installed at 40 locations from Alabama to Delaware over the Lower Coastal Plain, Upper Coastal Plain, and Piedmont/Interior Upland physiographic regions (Fig. 1). At any given location, only five treatments, including the control, were established. Each treatment was replicated four times per location. Plot sizes were approximately a 1/20 acre, however they varied in dimensions and were either circular or rectangular in design. The interior measurement plot contained a minimum of 24 planted "crop" trees while a 2-row or 15 foot buffer was added to the measurement plot to determine the perimeter of the treatment plot. Crop trees are defined as those expected to survive the entire rotation. They typically exclude trees that are badly suppressed, diseased, or with mechanical damage.

Table 1 depicts the average stand age, basal area, trees per acre, and dominant height for the study plots at the time of fertilization by physiographic region. During the analysis, a decision was made to inspect only the difference between the unfertilized control and the application of $200 \mathrm{lbs}$ of nitrogen and $50 \mathrm{lbs}$ of phosphorus $(200 \mathrm{~N}-50 \mathrm{P})$. The treatment (200N-50P-trace), which contained the additional application of micronutrients, was considered to be identical to the 200N-50P treatment. The plots were installed in 1973 or 1974 and Dbh and total height of all crop trees were measured every two years. Measurements terminated after a conclusion of 4 remeasurements or 8 years since treatment.

During data compilation and for reasons described below, 98 plots or $12 \%$ of the total number of plots were withdrawn from analysis since their attributes fell outside the normal operational ranges. After 8 years of treatment, if the plot still possessed the equivalent of 700 pine trees per acre, all plots measurements, including plot establishment were discarded, since the plantation mostly likely consisted of planted trees and naturally regenerated trees. If the ratio of 


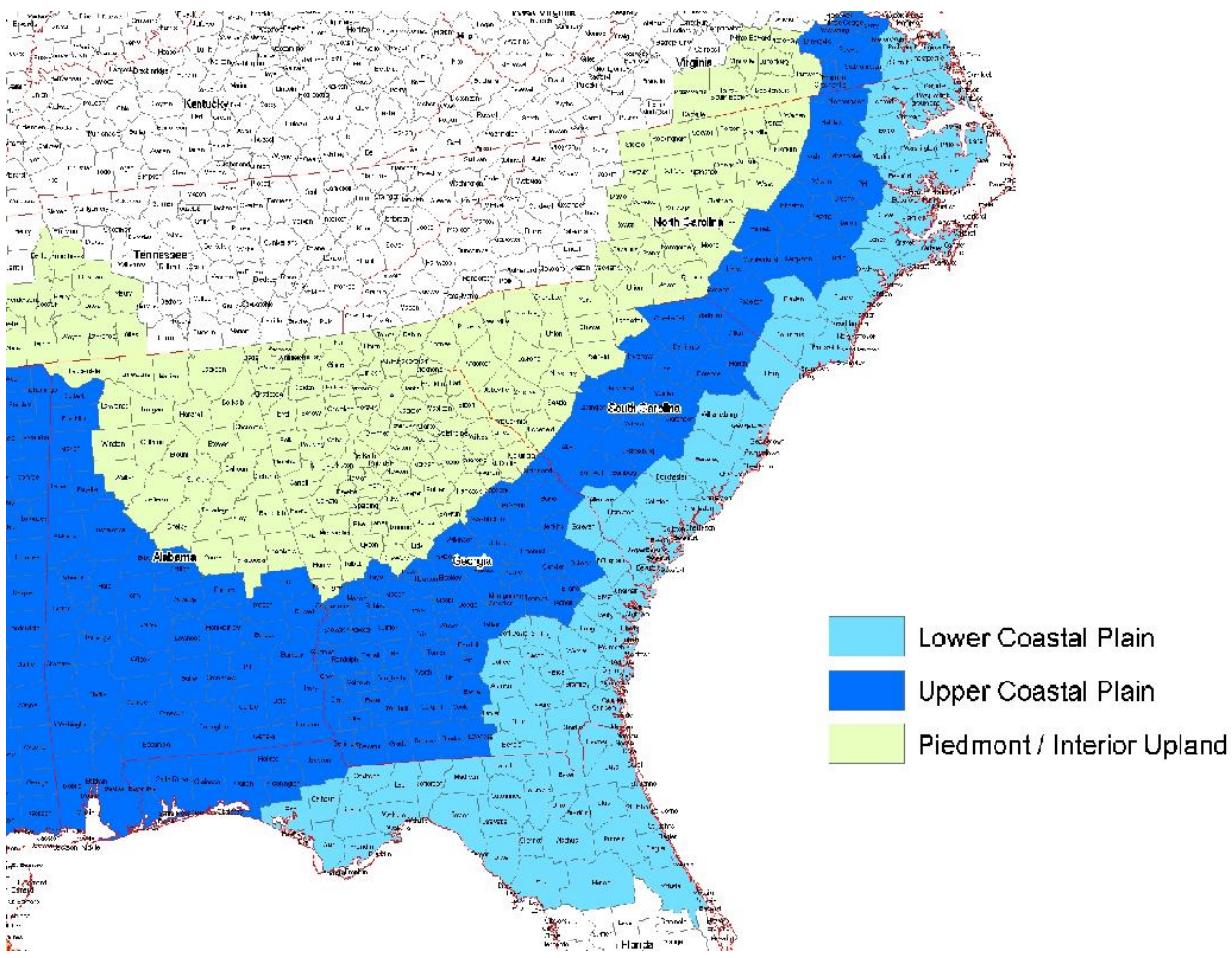

Fig. (1). The distribution of physiographic regions in southeastern United States.

hardwood basal area to total basal area exceeded 0.1 after 8 years of treatment, all plot measurements were discarded. Likewise if the ratio of hardwood trees per acre to total trees per acre exceeded 0.5, all plot measurements were discarded. Dominant height was computed using only loblolly pine trees and it was defined as the average height of the top 55\% of trees per plot ranked in descending order by height. Plots on the Pantego loam series in Columbus, Co. NC, which are considered to be extremely phosphorus deficient were also omitted from the study. Soil drainage classes were assigned to each study location based upon the physiographic region and soil taxonomic subgroup [13]. All Piedmont locations were considered to have upland soil drainage, while all Upper Coastal Plain locations were assigned the drainage class of 'well'. Most Lower Coastal Plain locations were assigned a drainage class of 'poor', with the exception of the Aquic Paleudult and Aquic Hapludult subgroups which were assigned the drainage class of 'well'.

A common function for modelling dominant height is the Hossfeld-Prodan-King model where dominant height $(\mathrm{H})$ is expressed as an inverse polynomial of age (A) $[14,15]$

$$
H=\frac{A^{2}}{\beta_{0}+\beta_{1} A+\beta_{2} A^{2}}
$$

The parameters are easily estimated with the following linear transformation

$$
\frac{A^{2}}{H}=\beta_{0}+\beta_{1} A+\beta_{2} A^{2}
$$

It was hypothesized that the linear height function above was suitable for modelling the untreated control (nonfertilized base stand). Both fertilized and unfertilized stands can be modelled with the following extension

$$
\frac{A^{2}}{H}=\beta_{0}+\beta_{1} A+\beta_{2} A^{2}+\beta_{3} y s t+\beta_{4} y s t^{2}+\beta_{5} x_{1} \sqrt{y s t}
$$

where

$$
\begin{array}{ll}
\text { yst }= & \text { years since treatment or fertilization; yst }= \\
0 \text { for untreated stands. }
\end{array}
$$

Table 1. Average Stand Attributes at the Time of Study Establishment and Fertilization by Physiographic Region

\begin{tabular}{|l|c|c|c|}
\hline \multicolumn{1}{|c|}{$\begin{array}{c}\text { Attributes at } \\
\text { Fertilization }\end{array}$} & $\begin{array}{c}\text { Lower } \\
\text { Coastal } \\
\text { Plain }\end{array}$ & $\begin{array}{c}\text { Upper } \\
\text { Coastal } \\
\text { Plain }\end{array}$ & $\begin{array}{c}\text { Piedmont/ } \\
\text { Interior } \\
\text { Upland }\end{array}$ \\
\hline \hline Stand age (years) & 3.9 & 3.9 & 5.4 \\
\hline Dominant height (ft) & 11.6 & 10.2 & 13.3 \\
\hline Pine basal area $\left(\mathrm{ft}^{2} / \mathrm{ac}\right)$ & 8.4 & 8.1 & 19.1 \\
\hline Hardwood basal area $\left(\mathrm{ft}^{2} / \mathrm{ac}\right)$ & 0.15 & 0.03 & 0.36 \\
\hline Pine trees/ac & 545 & 586 & 592 \\
\hline Hardwood trees/ac & 47 & 8 & 25 \\
\hline
\end{tabular}

Since the model above does not include an independent variable measuring site quality, it is plausible to believe that it is underspecified for stand-specific or plot-specific applications. Localizing the estimate to a specific stand or plot 
can be accomplished by using the analysis of covariance approach published by Bailey and Clutter [16] and later applied by Alder [17]. It should be noted however that these authors only reported the global parameters even though their grouping (cluster) variable was treated as a fixed effect. Extending the framework of the analysis of covariance model, it can be assumed that the plot-specific or standspecific coefficients are only a random sample of some population of possible coefficients, and that a mixed model technique should be used for fitting a random coefficient model. This concept may be pursued by considering Equation (2) for dominant height measured at age $\mathrm{k}$, from plot $\mathrm{j}$, and stand $\mathrm{i}$,

$$
\begin{aligned}
& \frac{A_{i j k}^{2}}{H_{i j k}}=\left(\beta_{0}+b_{0 i j}\right)+\left(\beta_{1}+b_{1 i}\right) A_{i j k}+\left(\beta_{2}+b_{2 i}\right) A_{i j k}^{2} \\
& +\beta_{3} y s t_{i j k}+\beta_{4} y s t_{i j k}+\beta_{5} x_{1} \sqrt{y s t_{i j k}}+e_{i j k}
\end{aligned}
$$

where

$\mathrm{b}_{0 \mathrm{ij}}=$ random variable that represents the difference between the intercept for the $\mathrm{j}^{\text {th }}$ plot in the $\mathrm{i}^{\text {th }}$ stand and the overall intercept $\beta_{0}$.

$\mathrm{b}_{1 \mathrm{i}}=$ random variable that represents the difference between the slope of the A covariate for the $i^{\text {th }}$ stand and the overall slope $\beta_{1}$.

$\mathrm{b}_{2 \mathrm{i}}=$ random variable that represents the difference between the slope of the $\mathrm{A}^{2}$ covariate for the $\mathrm{i}^{\text {th }}$ stand and the overall slope $\beta_{2}$.

$\mathrm{e}_{\mathrm{ijk}}=$ random error term assumed to be normally distributed

Since plots are nested within stands, the model above may be considered a multilevel linear mixed model [9]. It is known that

$$
\sum_{i=1}^{n} \sum_{j=1}^{n_{i}} b_{0 i j}=0 \quad \sum_{i=1}^{n} b_{1 i}=0 \quad \sum_{i=1}^{n} b_{2 i}=0
$$

where $n_{i}$ is the number of plots located in stand $i$ and $n$ equals the total number of stands.

$$
\beta_{0}+\beta_{1} A+\beta_{2} A^{2}+\beta_{3} y s t+\beta_{4} y s t^{2}+\beta_{5} x_{1} \sqrt{y s t} \text { is the fixed }
$$

effects part of the model and $b_{0 i j}+b_{1 i} A_{i j k}+b_{2 i} A_{i j k}^{2}+e_{i j k}$ is the random effects part of the model.

The mean value of the response is assumed to be linear in terms of the fixed effects parameters.

The random effects $b_{0 i j}$ and $b_{1 i}$ are assumed to be independent of the error term and one another since they occur at different levels. The same is true for the random effects $b_{0 \mathrm{ij}}$ and $b_{2 i}$. It must be assumed however that there exists within each stand a correlation between $b_{1 i}$ and $b_{2 i}$. As opposed to a fixed effects model, $e_{i j k}$ is no longer required to be distributed as $\sigma^{2}$ I. It should also be noted that the residuals of the mixed model are no longer required to sum to zero.

During the fitting process, no assumption was made about the structure of the variance associated with the ran- dom variables $b_{0 \mathrm{ij}}, \mathrm{b}_{1 \mathrm{i}}$, and $\mathrm{b}_{2 \mathrm{i}}$ (unstructured variance). An assumption was made however with respect to the within plot error structure for $\mathrm{e}_{\mathrm{ijk}}$. As previously mentioned, each plot was remeasured on 4 occasions for a total of 5 measurements per plot. The remeasurements, which are two years apart, lead inevitably to a positive autocorrelation, implying that an above average value on a plot is likely to be followed by another above average value. Failing to recognize the within plot correlation is not especially serious, since it is likely that the estimated parameters are unbiased. In the presence of autocorrelation, the precision of the estimators is usually overstated resulting in $p$-values that are too small [11]. Gregoire et al. [18] noted a marked improvement in the fit of a linear basal area prediction model of Douglas-fir when accounting for the within plot autocorrelation. Recognizing that many forestry studies have either missing measurements or a remeasurement schedule that varies from study to study, it was decided to model covariance structure of the error using exponential spatial covariance structure. When using the exponential spatial covariance structure in $\mathrm{SAS} \AA$, the value reported, $\phi$, is a function of the practical range of the temporal process. The range is also the time separation $\mathrm{n}$, when $\rho^{\mathrm{n}} \approx 0.05$. The time separation, $\mathrm{n}$, is equivalent to $3 \phi$. The within plot correlation is easily computed as

$$
\rho=e^{-\frac{1}{\varphi}}
$$

The inverse polynomial Hossfeld-Prodan-King model offers a convenient linear transformation for analyzing dominant height growth as a function of age. The obvious effect of site quality on dominant height at a plot or stand level is easily explained with a linear mixed model. Basal area is a more complex variable than dominant height and it is often modelled as a function of trees per acre, age, and dominant height. Nelder [19] suggested that the linear inverse polynomial could be used to explain plant growth and yield as a function of two or more factors. This approach was followed initially, however with rather poor results. Most likely the joint effect of age $(\mathrm{A})$, trees per acre $(\mathrm{N})$, and dominant height $(\mathrm{H})$ is misspecified with the transformation of $\left[\mathrm{A}^{2} \mathrm{~N}^{2} \mathrm{H}^{2} / \mathrm{B}\right]$, where $\mathrm{B}$ is basal area per acre.

Gregoire et al. [18], and Harrison and Borders [20] have used a popular linear transformation of the Schumacher-type equation to predict basal area

$$
\ln B=\beta_{0}+\beta_{1} \frac{1}{A}+\beta_{2} \ln N+\beta_{3} \ln H+\beta_{4} \frac{\ln N}{A}+\beta_{5} \frac{\ln H}{A}
$$

where $\ln$ is the base of natural logarithms. Clutter [21] added an apparent Hoerl-type response function to the base equation above to predict the basal area growth of fertilized and unfertilized stands

$$
R_{B}=\beta_{6}(y s t) e^{\beta_{7 y s t} \beta_{8}}
$$

He determined that the $\beta_{6}-\beta_{8}$ parameters were functions of the application rate of elemental nitrogen fertilizer. After adding the $R_{B}$ response to the Schumacher-type basal area prediction equation and transforming with anti-logarithms, 
the expression for basal area in fertilized and unfertilized stands becomes

$$
\left.B=e^{\beta_{0}+\beta_{1} / A} N^{\beta_{2}+\beta_{4} / A} H^{\beta_{3}+\beta_{5} / A}\left[e^{\beta_{6} y s t\left(e^{\beta_{7} y s t} \beta_{8}\right.}\right)\right]
$$

Two problems are inherent with this approach for predicting basal area:

1. The fertilization response is multiplicative rather than additive. ${ }^{1}$

2. There is no longer a biological interpretation of the $\beta_{6}-\beta_{8}$ parameters, since the derivative of $e^{R_{B}}$ with respect to yst can no longer be solved with a closedform solution as it involves an interaction with $\mathrm{A}, \mathrm{N}$, and $\mathrm{H}$.

Similar to Borders et al. [23], it was decided to model the basal area response with a nonlinear form of the Schumacher function and include $R_{B}$ as an additive response rather than a multiplicative response. Unlike the Gregoire et al. [18] model which included a random effect for the 1/A covariate, Equation (4) contains a random effect for the intercept and dominant height covariate. The nonlinear mixed model for basal area measured at age $\mathrm{k}$, from plot $\mathrm{j}$, and stand $\mathrm{i}$, is

$$
\begin{aligned}
& B_{i j k}=e^{\left\{\beta_{0}+b_{0 i j}\right\}+\beta_{1} / A_{i j k}} N_{i j k}^{\beta_{2}} H_{i j k}^{\left\{\beta_{3}+b_{3 i}\right\}+\beta_{4} / A_{i j k}} \\
& +\beta_{5}\left(y s t_{i j k}\right) e^{\beta_{6} y s t i j k}+e_{i j k}
\end{aligned}
$$

where

$b_{0 i j}=$ random variable that represents the rate of change between the intercept for the $\mathrm{j}^{\text {th }}$ plot in the $i^{\text {th }}$ stand and the overall intercept $\beta_{0}$.

$b_{3 \mathrm{i}}=$ random variable that represents the difference between the power of the $\mathrm{H}$ covariate for the $\mathrm{i}^{\text {th }}$ stand and the overall power $\beta_{3}$.

$\mathrm{e}_{\mathrm{ijk}}=$ random error term assumed to be normally distributed with mean 0 and variance $\sigma^{2}$

Since plots are nested within stands, the model above may be considered a multilevel nonlinear mixed model. This has an important consequence since the NLMIXED procedure of the SAS ${ }^{\circledR}$ system cannot accommodate multilevel nonlinear mixed models, and it becomes necessary to use the NLINMIX macro to estimate the parameters.

A preliminary analysis was conducted in this study using model (3) without random effects for the untreated control plots. It was quickly determined that the $\beta_{4}$ was not significantly different from zero. After fitting the reduced model without the $1 \mathrm{nN} / \mathrm{A}$ term, the estimated parameters of the re- maining terms were used as starting values for the nonlinear mixed model analysis. In addition to the ease in estimating the parameters with linear regression, one of the major reasons for the popularity of equation (3) is the stabilization of the variance and the promotion of homoscedasticity. Unless some corrective measures are made, the nonlinear formulation of Schumacher model in equation (4) frequently produces the classical megaphone shape or residual pattern. While the parameter estimates of heteroscedastic models are unbiased, they no longer have minimum variance. Two corrective measures were tested. The first employed a logarithmic transformation used by Lindstrom and Bates [24] that stabilizes the variance but does not linearize the parameters nor create a multiplicative response model:

$$
\ln B_{i j k}=\ln \left\{\begin{array}{l}
e^{\left\{\beta_{0}+b_{0 i j}\right\}+\beta_{1} / A_{i j k}} N_{i j k}^{\beta_{2}} H_{i j k}^{\left\{\beta_{3}+b_{3 i}\right\}+\beta_{4} / A_{i j k}} \\
+\beta_{5}\left(y s t_{i j k}\right) e^{\beta_{6} y s t i j k}
\end{array}\right\}+e_{i j k}
$$

With this analysis, both the $\beta_{5}$ and $\beta_{6}$ coefficients proved insignificant. Another technique involved the fitting of equation (4) setting the weight equal to the inverse square predicted value, or,

$$
W=\frac{1}{\hat{B}^{2}}
$$

Using this weighting variable, once again both the $\beta_{5}$ and $\beta_{6}$ coefficients proved insignificant. As a compromise, it was decided to use the following weight variable which assign large weights to observations with smaller variances but which does not mask the fertilizer response effect.

$$
W=\frac{1}{\hat{B}}
$$

\section{RESULTS}

\subsection{Dominant Height}

Estimated parameters of the fixed effects are expressed below in a transformed and extended expression of the Hossfeld-Prodan-King model. Fit statistics of the fixed effects and covariance terms of the random effects for the dominant height response model are presented in Tables $\mathbf{2}$ and $\mathbf{3}$ respectively.

$$
H=\frac{A^{2}}{0.75+0.2077 A+0.007588 A^{2}-0.09476 y s t+0.008065 y s t^{2}+0.1056 x_{1} \sqrt{y s t}}
$$

where

$$
\begin{aligned}
& \mathrm{H}=\quad \begin{array}{l}
\text { dominant height or average height of the } \\
\text { tallest } 55 \% \text { of loblolly pine trees. }
\end{array} \\
& \mathrm{A}=\quad \text { stand age in years } \\
& \mathrm{yst}=\begin{array}{l}
\text { years since treatment or fertilization; yst }= \\
0 \text { for untreated stands. }
\end{array} \\
& \mathrm{x}_{1}=\quad \begin{array}{l}
1 \text { if soil type is a well drained Coastal } \\
\text { Plain; } 0 \text { otherwise }
\end{array}
\end{aligned}
$$

\footnotetext{
${ }^{1}$ The multiplicative modelling approach to fertilization was also adopted by Hynynen et al. [22]. An indirect consequence of the technique is that stands of higher site quality have larger predicted fertilization responses.
} 
Table 2. Fit Statistics of Equation (2) for the Fixed Effects Parameters

\begin{tabular}{|c|c|c|c|c|c|}
\hline \multicolumn{7}{|c|}{ Solution for Fixed Effects } \\
\hline Effect & Estimate & Standard Error & DF & $\mathbf{t}$ Value & Pr $>|\mathbf{t}|$ \\
\hline \hline Intercept & 0.7500 & 0.05220 & 645 & 14.37 & $<.0001$ \\
\cline { 2 - 6 } $\mathbf{A}$ & 0.2077 & 0.02162 & 54.3 & 9.60 & $<.0001$ \\
\hline $\mathbf{A}^{2}$ & 0.007588 & 0.001159 & 53.6 & 6.55 & $<.0001$ \\
\hline $\mathbf{y s t}^{\mathbf{y}}$ & -0.09476 & 0.01326 & 519 & -7.15 & $<.0001$ \\
\hline $\mathbf{y s t}^{\mathbf{2}}$ & 0.008065 & 0.001470 & 518 & 5.49 & $<.0001$ \\
\hline$x_{1} \sqrt{y_{s t}}$ & 0.1056 & 0.02710 & 293 & 3.90 & 0.0001 \\
\hline
\end{tabular}

An inspection of the conditional studentized residuals in Fig. (2), reveals that the estimated model does not depart substantively from assumption of normal residuals. Conditional residuals equal the observed value minus the predicted value from both the fixed and random effects.

\subsection{Basal Area}

Estimated parameters of the fixed effects are expressed in the equation below.

$$
B=e^{-3.07-17.9169 / A} N^{0.6509} H^{0.9675+5.121 / A}+1.6369(y s t) e^{-0.1360 y s t}
$$

where

$$
\begin{array}{ll}
\mathrm{B}= & \text { basal area in } \mathrm{ft}^{2} / \text { acre } \\
\mathrm{A}= & \text { stand age in years } \\
\mathrm{N}= & \text { trees per acre } \\
\mathrm{H}= & \text { dominant height } \\
\mathrm{yst}= & \begin{array}{l}
\text { years since treatment or fertilization; yst } \\
=0 \text { for untreated stands. }
\end{array}
\end{array}
$$

Fit statistics of the fixed effects and covariance terms of the random effects for the basal area response model are presented in Tables $\mathbf{4}$ and $\mathbf{5}$ respectively.

The response predicts the additional increase in basal area per acre beyond the contribution already explained in the basal area equation by the independent dominant height variable, $\mathrm{H}$. The maximum response is predicted to occur 7.4 years after fertilization with an additional marginal response of $4.4 \mathrm{ft}^{2} / \mathrm{ac}$.

Table 3. Covariance Parameter Estimates of the Dominant Height Response Model

\begin{tabular}{|c|c|c|}
\hline Covariance Parameter & Subject or Cluster & Estimate \\
\hline \hline$\sigma_{b_{0 i j}}^{2}$ & Plot & 0.01801 \\
\hline$\sigma_{b_{1 i}}^{2}$ & Stand & 0.008548 \\
\hline$\sigma_{b 1 i, b 2 i}$ & Stand & -0.00034 \\
\hline$\sigma_{b_{2 i}}^{2}$ & Stand & 0.000021 \\
\hline$\varphi$ (range) & Plot & $7.8380, \rho=0.88$ \\
\hline$\sigma^{2}$ (residual) & & 0.04309 \\
\hline
\end{tabular}

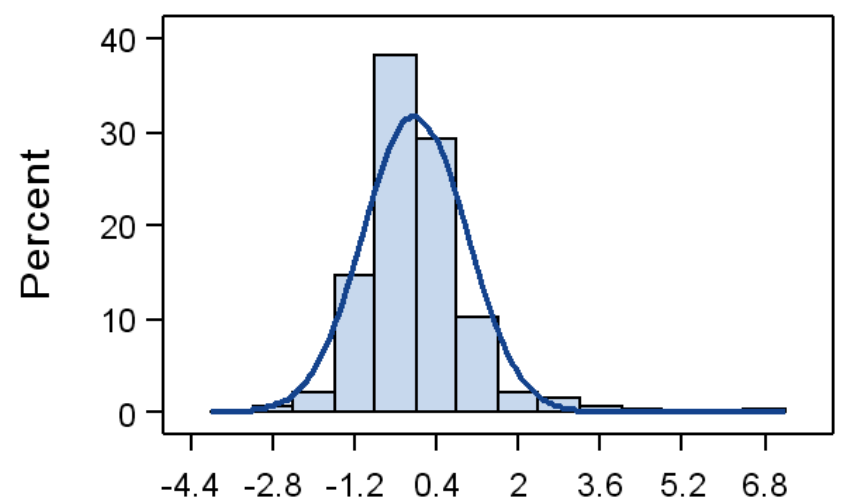

\section{Studentized Residual}

Fig. (2). A histogram of the conditional studentized residuals of Equation (2) with Normal probability density overlaid.

An inspection of the modified residuals in Fig. (3), reveals that the estimated model does not depart from assumption of normal residuals. The modified residuals presented here are also known as pseudo-data and are based on a Taylor series expansion around zero (the expected value of the random effects).

Table 4. Fit Statistics of Equation (4) for the Fixed Effects Parameters

\begin{tabular}{|c||c|c|c|c|c|c|c|c|}
\hline \multicolumn{9}{|c|}{ Solution for Fixed Effects } \\
\hline Parameter & Estimate & Standard Error & DF & t Value & Pr $>|\mathbf{t}|$ & Alpha & Lower & Upper \\
\hline \hline \multicolumn{1}{|c||}{$\boldsymbol{\beta}_{\mathbf{0}}$} & -3.0700 & 0.3597 & 421 & -8.54 & $<.0001$ & 0.05 & -3.7770 & -2.3630 \\
\hline $\boldsymbol{\beta}_{\mathbf{1}}$ & -17.9169 & 0.7480 & 339 & -23.95 & $<.0001$ & 0.05 & -19.3883 & -16.4456 \\
\hline $\boldsymbol{\beta}_{\mathbf{2}}$ & 0.6509 & 0.04082 & 443 & 15.95 & $<.0001$ & 0.05 & 0.5707 & 0.7311 \\
\hline $\boldsymbol{\beta}_{\mathbf{3}}$ & 0.9675 & 0.05382 & 337 & 17.97 & $<.0001$ & 0.05 & 0.8616 & 1.0734 \\
\hline $\boldsymbol{\beta}_{\mathbf{4}}$ & 5.1210 & 0.2830 & 416 & 18.09 & $<.0001$ & 0.05 & 4.5646 & 5.6774 \\
\hline $\boldsymbol{\beta}_{\mathbf{5}}$ & 1.6369 & 0.5256 & 404 & 3.11 & 0.0020 & 0.05 & 0.6036 & 2.6702 \\
\hline $\boldsymbol{\beta}_{\mathbf{6}}$ & -0.1360 & 0.06803 & 489 & -2.00 & 0.0462 & 0.05 & -0.2696 & -0.00231 \\
\hline
\end{tabular}




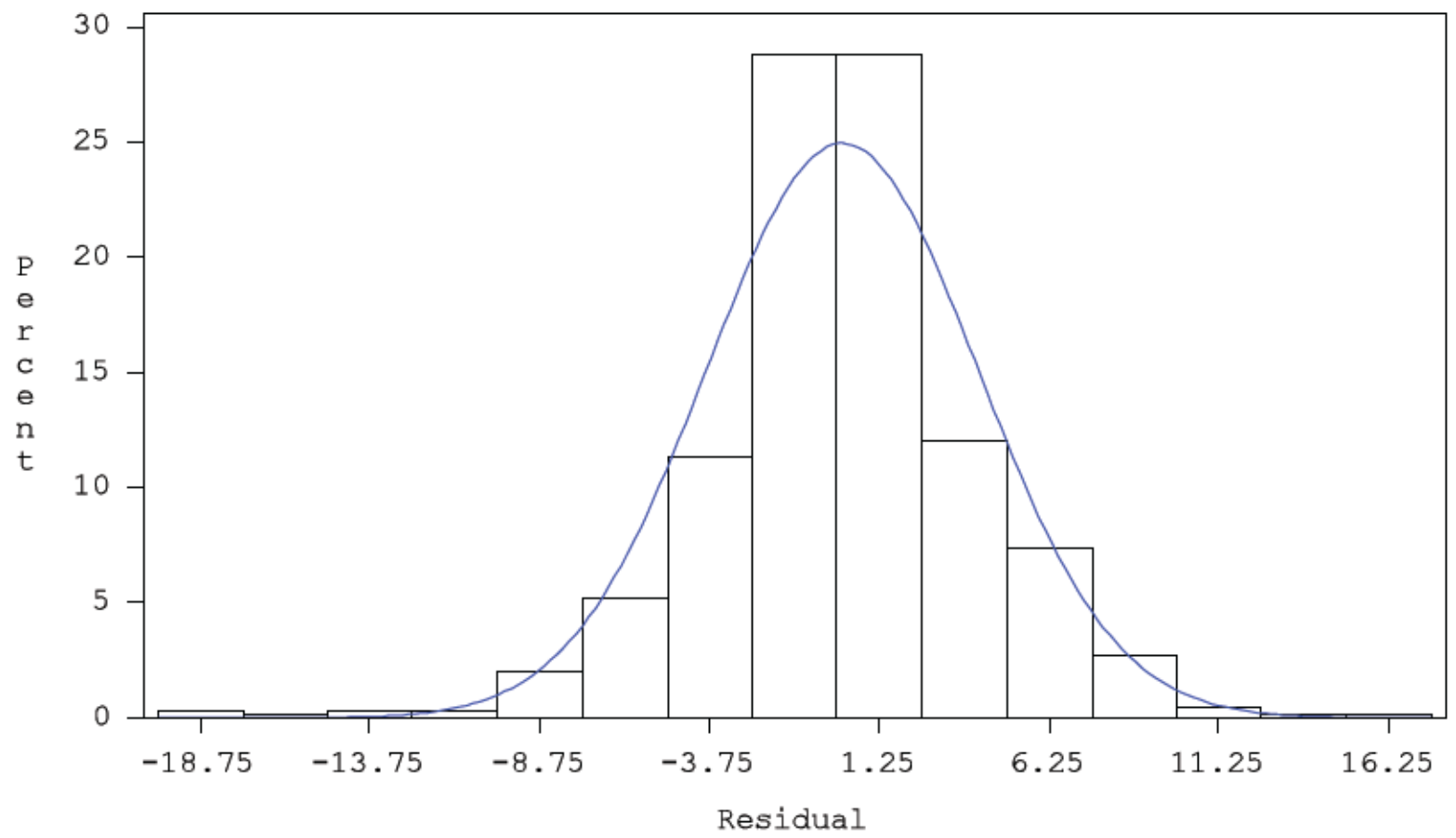

Fig. (3). A histogram of the modified residuals of Equation (4) with Normal probability density overlaid.

\section{DISCUSSION}

The ability to detect a basal area treatment response to juvenile fertilization can be attributed to the adoption of the nonlinear mixed modelling technique of Equation (4). When the random effects are omitted from Equation (4) and only the $\beta_{1}-\beta_{6}$ parameters of the fixed effects are estimated with weighted nonlinear regression, the estimated $\beta_{6}$ parameter is not significantly different from zero and the solution fails to converge. Only when the weight is set to equal 1 , does the nonlinear regression model converge and furnish a significant estimate of $\beta_{6}$.

Table 5. Covariance Parameter Estimates of the Basal Area Response Model

\begin{tabular}{|c|c|c|}
\hline Covariance Parameter & Subject or Cluster & Estimate \\
\hline \hline$\sigma_{b_{0 i j}}^{2}$ & Plot & 0.003850 \\
\hline$\sigma_{b_{3 i}}^{2}$ & Stand & 0.001284 \\
\hline$\varphi$ (range) & Plot & $1.5426, \rho=0.52$ \\
\hline$\sigma^{2}$ (residual) & & 0.5023 \\
\hline
\end{tabular}

It is not too surprising that efforts to stabilize the variance also undermine the ability to detect a large difference between an unfertilized stand and a fertilized stand, since the greatest spread between the treated and untreated stand occur at 7-8 years after treatment when the stand is the largest. The compromise proposed here between modelling the fertilization response and attenuating the unequal variance seems reasonable. In general, the largest predicted gains in basal area in fertilized stands occur because of the increase of dominant height rather than the marginal accretion due to the term: 1.6369 (yst) $\mathrm{e}^{-0.136 y s t}$.

The predicted gains in dominant height are approximately 2 feet for stands fertilized at age 4 and grown until age 12 on Piedmont upland soils and poorly drained soils in the Coastal Plain. As depicted in Table 6, the predicted height gains are much less on well drained Coastal Plain soils. $^{2}$ In fact, the dominant height model must be constrained for response periods surpassing ten years (yst $>10$ ) on the well drained Coastal Plain soils so that the predicted dominant height of fertilized stands does not fall below that of unfertilized stands.

The expected gain from juvenile fertilization $(200 \mathrm{~N}-50 \mathrm{P})$ is modest. Previous efforts to extract useful information from the Region-wide 2 study were hampered by the installation design that permitted large differences in initial stocking and the use of very small plots for measuring fertilization response. The model described here were successful in reducing unexplained variation and detecting a dominant height response.

The predicted gain in basal area from juvenile fertilization (200N-50P) is moderate. For Piedmont upland soils and poorly drained Coastal Plain soils, a stand fertilized at age 4 is expected to have 11.7 additional $\mathrm{ft}^{2} / \mathrm{ac}$ in basal area over that of an unfertilized stand at age 12. Fig. (4) displays the source of the gain in basal area on a stand with a site index of 75 in the Piedmont or poorly drained Coastal Plain.

\footnotetext{
${ }^{2}$ Based on recent measurements and observed fertilizer responses of forest stands in the well drained Coastal Plain soil type in the Region-wide 18 study, Dr. H. Lee Allen of North Carolina State University, Forest Nutrition Cooperative, has recommended that the results are modified so that: dominant height response of well drained Coastal Plain $=0.7 \mathrm{x}$ predicted dominant height response of poorly drained Coastal Plain soil type.
} 


\section{Loblolly Pine Fertilized at Age 4}

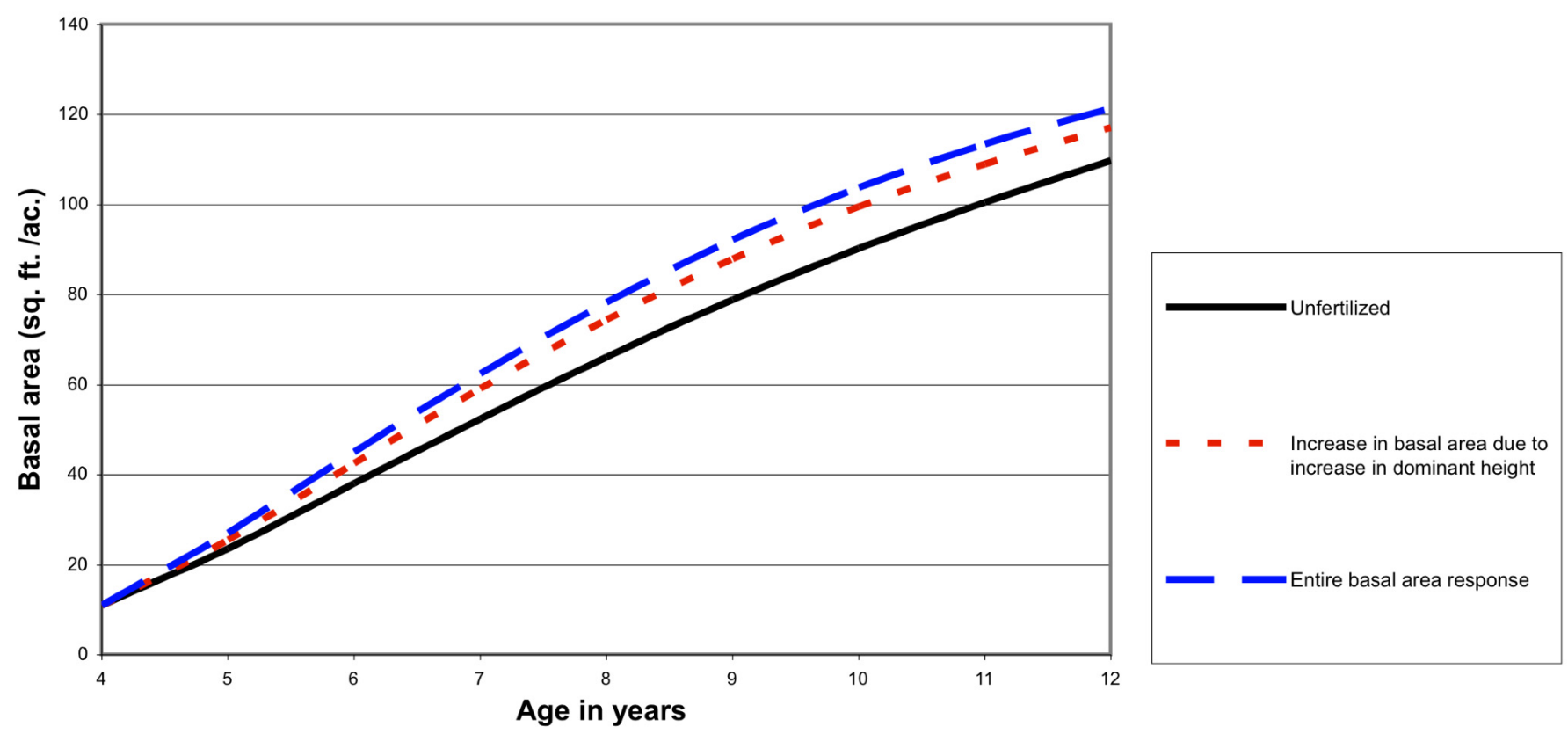

Fig. (4). Predicted basal area in $\mathrm{ft}^{2} / \mathrm{ac}$ for a loblolly pine stand with a site index of 75 . A large portion of the predicted gains in basal area in fertilized stands occur because of the increase of dominant height.

Table 6. Predicted Dominant Height in Feet for Loblolly Pine Stands with a Site Index of 75 that are Fertilized at Age 4

\begin{tabular}{|c|c|c|c|}
\hline $\begin{array}{c}\text { Stand } \\
\text { Age }\end{array}$ & $\begin{array}{c}\text { Dominant } \\
\text { Height of } \\
\text { Unfertilized } \\
\text { Stands }\end{array}$ & $\begin{array}{c}\text { Dominant Height } \\
\text { of Fertilized Stands } \\
\text { in Piedmont/Interior } \\
\text { Upland or Poorly } \\
\text { Drained Coastal } \\
\text { Plain Soil Type }\end{array}$ & $\begin{array}{c}\text { Dominant Height } \\
\text { of Fertilized Stands } \\
\text { in Well Drained } \\
\text { Coastal Plain } \\
\text { Soil Type }\end{array}$ \\
\hline \hline 4 & 18.8 & 18.8 & 18.8 \\
\hline 5 & 22.4 & 23.0 & 22.4 \\
\hline 6 & 25.9 & 27.1 & 26.4 \\
\hline 7 & 29.2 & 30.9 & 29.4 \\
\hline 8 & 32.4 & 34.5 & 32.7 \\
\hline 9 & 35.5 & 37.8 & 35.8 \\
\hline 10 & 38.5 & 40.8 & 38.6 \\
\hline 11 & 41.5 & 43.6 & 41.5 \\
\hline 12 & 44.2 & 46.1 & 44.2 \\
\hline
\end{tabular}

\section{REFERENCES}

[1] Bailey RL, Burgan TM, Jokela EJ. Fertilized midrotation-aged slash pine plantations - stand structure and yield prediction models. South J Appl Forest 1989; 13: 76-80.

[2] Pienaar LV, Rheney JW. Modeling stand level growth and yield response to silvicultural treatments. Forest Sci 1995; 41: 629-38.

[3] Wenger KF, Ed. Forestry Handbook. Edited for Society of American Foresters. New York: John Wiley \& Sons; 1984.

[4] Sit V, Poulin-Costello M. Catalog of curves for curve fitting. British Columbia, Ministry of Forests, Research Branch. Biometrics Information Handbook Series, No. 4. 1994.

[5] Ratkowsky DA, Ed. Handbook of nonlinear regression models. New York: Marcel Decker; 1990
[6] Morris LA, Lowery RF. Influence of site preparation on soil conditions affecting stand establishment and tree growth. South J App Forest 1988; 12: 170-8.

[7] Buford MA, Burkhart HE. Genetic improvement effects on growth and yield of loblolly pine plantations. Forest Sci 1987; 33: 707-24.

[8] Amateis R, Liu J, Ducey MJ, Allen HL. Modeling response to midrotation nitrogen and phosphorus fertilization in loblolly pine plantations. South J Appl Forest 2000; 24: 207-12.

[9] Hall DB, Bailey RL. Modeling and prediction of forest growth variables on multilevel nonlinear mixed models. Forest Sci 2001; 47: 311-21.

[10] Fang Z, Bailey RL. A multivariate simultaneous prediction system for stand growth and yield with fixed and random effects. Forest Sci 2001; 47: 550-62.

[11] Schabenberger O, Pierce FJ, Eds. Contemporary statistical models for the plant and soil sciences. Boca Raton: CRC Press; 2001.

[12] Haines LW, Ed. Second region-wide study plan. North Carolina State Forest Fertilization Cooperative: North Carolina State University. 1972.

[13] Allen HL. Compilation of Region-wide 2 individual study reports. North Carolina State University. North Carolina State Forest Fertilization Cooperative Report 1982; No. 13.

[14] King JE. Site index curves for Douglas-fir in the Pacific Northwest. Weyerhaeuser Forestry Paper 1996; No. 8.

[15] Kiviste A, Álvarez González JG, Rojo Alboreca A, Ruíz González $\mathrm{AD}$. Funciones de crecimiento de aplicación en el ámbito forestal Monografías INIA Forestal. $\mathrm{N}^{\circ} 4$. Madrid: Ministerio de Ciencia y Tecnología. Instituto Nacional de Investigación y Tecnología Agraria y Alimentaria; 2002.

[16] Bailey RL, Clutter JL. Base-age invariant polymorphic site curves. Forest Sci 1974; 20 : 155-9.

[17] Adler D. Forest volume estimation and yield prediction, vol. 2 yield prediction. Food and Agriculture Organization of the United Nations. 1980; FAO For. Pap. 22/2.

[18] Gregoire TG, Schabenberger O, Barrett JP. Linear modeling of irregularly spaced, unbalanced, longitudinal data from permanentplot measurements. Can J For Res 1995; 25: 137-56.

[19] Nelder JA. Inverse polynomials, a useful group of multi-factor response functions. Biometrics 1966; 22:128-41.

[20] Harrison WM, Borders BE. Yield prediction and growth projection for site-prepared loblolly pine plantations in the Carolinas, Georgia, Alabama, and Florida. University of Georgia, Warnell School of 
Forest Resources, Plantation Management Research Cooperative.1996; PMRC Tech. Rpt. 1996-1.

[21] Clutter ML. A growth and yield model for intensively managed loblolly pine plantations. Unpublished Ph.D. dissertation. Athens, Georgia: University of Georgia USA; 1993.

[22] Hynynen J, Burkhart HE, Allen HL. Modelling tree growth in fertilized midrotation loblolly pine plantations. For Ecol Manage 1998; 107: 213-29.
[23] Borders BE, Harrison WH, Zhang Y, Shiver BD, Clutter M, Cieszewski C, Daniels RF. Growth and yield models for second rotation loblolly pine plantations in the Piedmont/Upper Coastal Plain and Lower Coastal Plain of the southeastern U.S. University of Georgia, Warnell School of Forest Resources, Plantation Management Research Cooperative. 2004; PMRC Tech. Rpt. 2004-4, Athens, GA.

[24] Lindstrom MJ, Bates DM. Nonlinear mixed effects models for repeated measures data. Biometrics 1990; 46: 673-87.

(C) John P. McTague; Licensee Bentham Open.

This is an open access article licensed under the terms of the Creative Commons Attribution Non-Commercial License (http: //creativecommons.org/licenses/by-nc/

3.0/) which permits unrestricted, non-commercial use, distribution and reproduction in any medium, provided the work is properly cited. 